\title{
NSAID gastroenteropathy: Past, present and future
}

\author{
JOHN L WALLACE PhD
}

\begin{abstract}
JL WALLACE. NSAID gastroenteropathy: Past, present and future. Can J Gastroenterol 1996;10(7):451-459. The toxicity of nonsteroidal anti-inflammatory drugs (NSAIDs) in the gastrointestinal tract continues to be a major limitation to their use in the treatment of inflammatory disorders. Better understanding of the pathogenesis of NSAID enteropathy has facilitated the development of novel NSAIDs that spare the gastrointestinal tract. In particular, identification and characterization of the inducible form of prostaglandin synthase has led to the design of novel NSAIDs that specifically target that enzyme. The pathogenesis of NSAID gastroenteropathy is reviewed, as are the strategies that have been used in the past and are used now to develop NSAIDs that spare the gastrointestinal tract. Also reviewed are the strategies being employed to achieve this goal in the future.
\end{abstract}

Key Words: Cyclo-oxygenase, Nitric oxide, Nonsteroidal antiinflammatory drug, Prostaglandins, Ulcer

\section{Gastro-entéropathie associée aux AINS : le passé, le présent et l'avenir}

RÉSUMÉ : La toxicité des anti-inflammatoires non stéroïdiens (AINS) dans le tractus digestif continue de restreindre considérablement leur emploi dans le traitement des troubles inflammatoires. Une meilleure compréhension de la pathogenèse de l'entéropathie associée aux AINS a facilité la mise au point de nouveaux AINS qui sont plus doux pour les voies digestives. En particulier, l'identification et la caractérisation d'une forme inductible de prostaglandine synthase ont permis la création de nouveaux AINS qui visent spécifiquement cette enzyme. La pathogenèse de la gastro-entéropathie associée aux AINS est passée en revue, tout comme les stratégies qui ont été utilisées dans le passé et qui sont utilisées présentement pour mettre au point des AINS qui n'affectent pas les voies digestives. Nous passons également en revue les stratégies utilisées pour atteindre cet objectif à l'avenir.
$\mathrm{N}$ onsteroidal anti-inflammatory drugs (NSAIDs) are among the most commonly prescribed drugs in North America (about 10 million prescriptions per year in Canada), as well as being used extensively as over-the-counter preparations. While their major use is as anti-inflammatory and analgesic agents, they are also widely used for antipyretic effects, and in the case of acetylsalicylic acid (ASA), for antithrombotic indications. However, long term use of NSAIDs is associated with a high risk of gastrointestinal injury. While the gastrointestinal adverse effects of NSAIDs are usually associated with the use of relatively high doses for relief of the pain and inflammation associated with rheumatoid arthritis, even very low doses of ASA for prophylaxis of myocardial infarction and stroke are associated with a significant increase in the risk of gastrointestinal bleeding.

Numerous strategies have been employed over the past 30 or 40 years to develop NSAIDs that spare the gastrointesti- nal tract. Until recently, none of these strategies markedly affected the incidence of clinically significant adverse reactions to NSAIDs. However, data from recent studies suggest that current strategies for the development of gastrointestinal-safe NSAIDs may be at least partially successful. In this review, the strategies that have been employed in the past and those currently being used are reviewed, as are some of the strategies that are being considered for development of NSAIDs in the future.

\section{MECHANISM OF BENEFICIAL ACTIONS OF NSAIDs}

Since the discovery by Vane (1) in 1971 that ASA and a number of different NSAIDs blocked the production of prostaglandins, it has become firmly established that that is the major reason for the anti-inflammatory, analgesic, antipyretic and antithrombotic actions of these drugs. The three- 
dimensional structure of the enzyme cyclo-oxygenase (prostaglandin synthase) has been demonstrated, and the channel in the enzyme into which arachidonic acid binds has been identified (2). NSAIDs block the access of arachidonic acid to this binding site, thereby preventing the conversion of arachidonic acid to prostaglandins and thromboxane. ASA, on the other hand, modifies the shape of the binding channel for arachidonic acid by acetylating a serine residue on cyclo-oxygenase.

There is some debate regarding the mechanism responsible for the anti-inflammatory effects of ASA (3). This controversy has focused largely on the fact that ASA has an extremely short half-life in the plasma (less than 15 mins) and is converted to salicylate, which is a very weak inhibitor of cyclo-oxygenase. Therefore, how can ASA exert anti-inflammatory and antipyretic effects for several hours after ingestion and why does salicylate exert anti-inflammatory activity? It is becoming clear that in addition to suppressing cyclo-oxygenase enzyme activity, ASA and salicylate can inhibit induction of cyclo-oxygenase at sites of inflammation (4). This is discussed in more detail below.

\section{HOW BIG IS THE PROBLEM?}

Estimates of the incidence of NSAID-induced gastropathy vary greatly. Lanza (5) estimates the incidence to be between $15 \%$ and $20 \%$ of chronic NSAID users, while others have suggested that the incidence of symptomatic ulcers and potentially life-threatening consequences is $2 \%$ to $4 \%$ in patients taking NSAIDs for a year (6). The large differences in these estimates depend mainly on how 'ulcer' is defined in each study. For example, in a study by Graham et al (7) of the protective effects of misoprostol against NSAID-induced gastric injury, an ulcer was defined as a break in the mucosa of greater than $3 \mathrm{~mm}$ in diameter. Others might define such damage as an erosion rather than an ulcer. Some studies focus on the 'clinical significant adverse effects' of NSAIDs, such as perforation, bleeding requiring hospitalization or gastric outlet obstruction. In a recent study involving over 4000 patients taking NSAIDs over six months, $0.9 \%$ exhibited these clinically significant adverse effects (8).

Another problem regarding the incidence of NSAID gastropathy is that the majority of patients with endoscopically detectable NSAID-induced gastric damage are completely asymptomatic (7). It is possible that this phenomenon is attributable to the analgesic properties of NSAIDs masking any pain associated with the injury, but this has not been firmly established.

The incidence of NSAID-induced small bowel damage is even more difficult to define accurately. Intestinal bleeding has been suggested to occur in up to $65 \%$ of patients chronically taking NSAIDs (9), and significant permeability changes have been reported to be common and to persist for as long as 16 months after cessation of NSAID therapy (10). On the other hand, adverse events, such as the development of NSAID-induced intestinal strictures, are very rare (11). NSAIDs can exacerbate pre-existing colitis and cause a relapse of quiescent inflammatory bowel dis- ease (12) but there are no data available on how frequently this occurs.

An alternative to attempting to define the prevalence or incidence of NSAID-induced gastroenteropathy is to consider the financial costs of these adverse effects. The cost of NSAID gastropathy in the United States' arthritic population alone has been estimated to be US $\$ 4$ billion annually (13), and the cost of renal complications of NSAID use - while occurring less frequently - is likely to exceed this amount.

\section{PATHOGENESIS}

It is highly likely that the ulcerogenic effects of NSAIDs are directly related to their ability to suppress prostaglandin synthesis in the stomach. Prostaglandins play an important role in the gastrointestinal tract: they mediate several components of mucosal defence (bloodflow, mucus and bicarbonate secretion, and mucosal immunocyte function) (14). There is a good correlation between the ability of an NSAID to suppress gastric prostaglandin synthesis and its ulcerogenic actions (15). There is also a dose dependency of both suppression of prostaglandin synthesis in the stomach and ulcerogenic activity (15). Some NSAIDs, including ASA, also have topical irritant properties that may contribute to their ability to damage the gastric mucosa. This topical irritancy is predominantly seen in acidic NSAIDs, and may be related in part to the observation that these compounds can accumulate in gastrointestinal epithelial cells due to the phenomenon of 'ion trapping' $(16,17)$ and/or their ability to uncouple oxidative phosphorylation in epithelial cells (17). However, topical irritant properties of NSAIDs do not appear to make a major contribution to the ability of these agents to produce clinically significant gastric ulceration, since similar adverse effects are observed following parenteral or rectal administration of NSAIDs $(18,19)$. A further feature of NSAIDs that likely contributes to the bleeding that is sometimes observed in patients chronically ingesting these drugs is their inhibitory effects on platelet aggregation through the suppression of thromboxane synthesis $(20,21)$.

In experimental NSAID gastropathy there is convincing evidence that neutrophil has a role in producing mucosal injury (Figure 1). Work in the author's laboratory and that of others suggests that administration of NSAIDs results in an increase in the number of neutrophils adhering to the vascular endothelium in the gastric and mesenteric microcirculation (22-26). Experimental NSAID gastropathy was markedly reduced in neutropenic rats $(27,28)$, and treatment with monoclonal antibodies, which prevent neutrophil adherence to the vascular endothelium, markedly attenuated the severity of NSAID gastropathy in rats and rabbits $(22,29)$. Furthermore, cytoprotective prostaglandins prevented NSAIDinduced leukocyte adherence $(24,25)$.

NSAID-induced leukocyte adherence could contribute to gastric mucosal injury in two major ways (30). First, adherence of neutrophils to the vascular endothelium would likely be accompanied by activation of these cells, leading to the liberation of oxygen-derived free radicals and proteases. These substances could mediate much of the endothelial and 


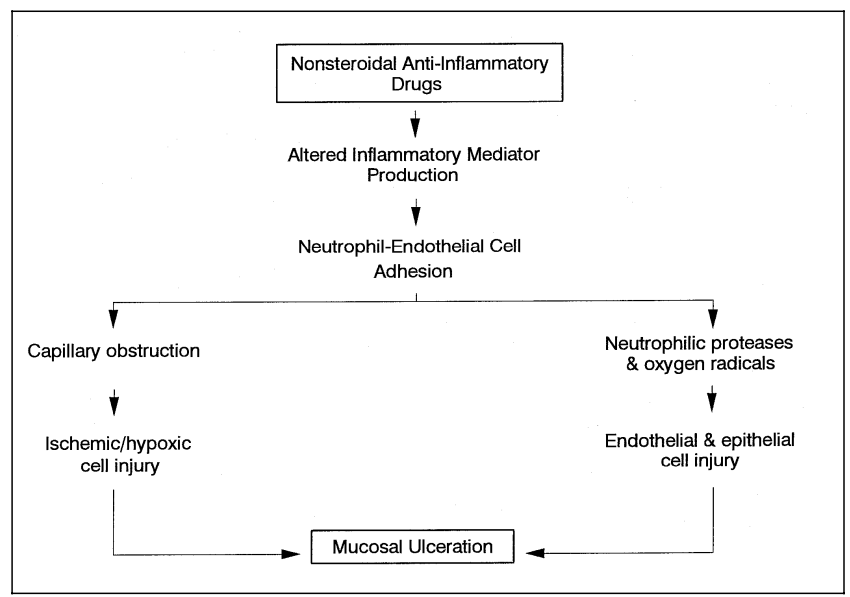

Figure 1) Role of neutrophils in the pathogenesis of nonsteroidal antiinflammatory drug (NSAID)-induced gastric mucosal injury. NSAIDs suppress prostaglandin synthesis and may augment release of other inflammatory mediators, such as leukotriene $\mathrm{B}_{4}$ and tumour necrosis factor. This alteration in mediator production leads to enhanced neutrophil adherence to the vascular endothelium, which can contribute to mucosal injury in two major ways. First, when neutrophils adhere they become activated and release reactive oxygen metabolites and proteases, both of which can cause endothelial and epithelial damage. Second, adherence of neutrophils can lead to capillary obstruction and to reduced mucosal bloodflow, leading to ischemic/hypoxic cell injury

epithelial injury caused by NSAIDs. Second, neutrophil adherence to the vascular endothelium could lead to capillary obstruction, resulting in a reduction in gastric mucosal bloodflow and thereby predisposing the mucosa to injury. A reduction in gastric bloodflow following NSAID administration has been reported by many groups (31-33) and has been shown to occur after the appearance of 'white thrombi' in the gastric microcirculation (31). Whether neutrophils contribute to NSAID-induced gastric mucosal injury in humans has yet to be investigated.

The pathogenesis of small intestinal damage induced by NSAIDs is less well understood than the pathogenesis of gastric injury (Figure 2). There is reasonable evidence that the injury to the small intestine is produced through completely different mechanisms. The suppression of prostaglandin synthesis by NSAIDs does not appear to be a major contributor to the production of mucosal injury in the small intestine (34). There is evidence that bile contributes to NSAID enteropathy (35) and that enteric bacteria has a role (36). With respect to the latter, various antibiotics have been shown to reduce the severity of experimental NSAID enteropathy (35) and, in one clinical study, to decrease the epithelial permeability changes induced by an NSAID (37). Furthermore, the severity of NSAID enteropathy is markedly reduced in rats raised in germ-free conditions (38). It has been suggested that NSAIDs, which are acidic, are more likely to cause damage in the small intestine, similar to the topical irritant properties in the stomach. Whether an NSAID undergoes enterohepatic recirculation also appears to be a primary determinant of its potential to cause small bowel injury (39).

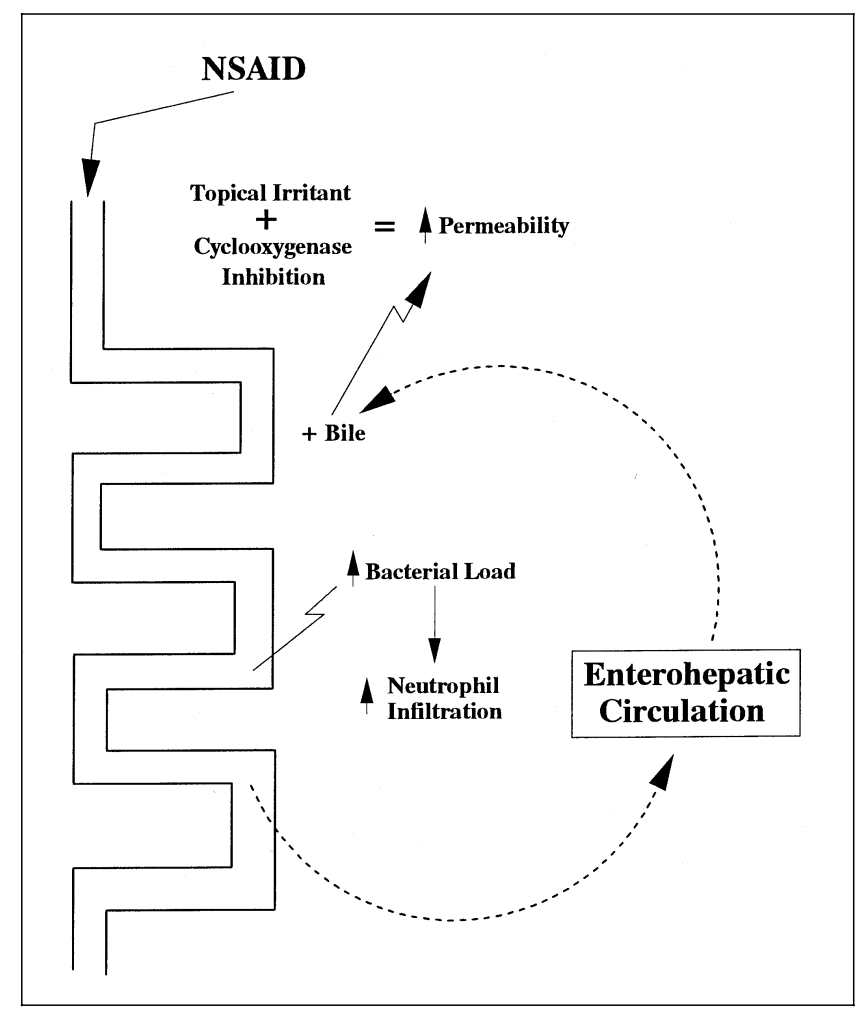

Figure 2) Schematic representation of the major factors in the pathogenesis of nonsteroidal anti-inflammatory drug (NSAID)-induced enteropathy. NSAIDs can elevate epithelial permeability, possibly through suppression of prostaglandin synthesis but more likely via their topical irritant properties (particular for acidic NSAIDs). Bile may also contribute to the epithelial injury caused by NSAIDs. Bacterial numbers with the intestine increase during NSAID administration and likely exacerbate the injury. Enterohepatic circulation of the NSAID leads to repeated damage to the epithelium and augments the increase in bacterial numbers

\section{PROPHYLACTIC THERAPY}

Before reviewing various strategies for developing NSAIDs that don't cause gastrointestinal damage, it is worthwhile considering the question of whether the injury caused by existing NSAIDs can be prevented through prophylaxis with another agent. Essentially two approaches to prophylaxis have been taken. First, based on the belief that acid plays a role in the pathogenesis of NSAID gastropathy, it has long been suggested that suppression of acid secretion prevents the development of ulcers during NSAID therapy. However, while numerous studies have convincingly shown a beneficial effect of prophylaxis against duodenal ulcer formation, a significant protective effect against gastric ulcer formation has not been demonstrated $(40,41)$. Similarly, omeprazole has been shown to reduce the incidence of NSAID-induced gastric erosions (42), but efficacy in preventing gastric ulcers has not yet been demonstrated.

The second approach to prophylaxis is the administration of exogenous prostaglandins to replenish the mucosal 'supply' of this substance caused by the NSAID. Misoprostol, a prostaglandin $\mathrm{E}_{1}$ analogue, markedly reduces the incidence of NSAID-induced gastric (7) and duodenal ulcers (43). The former study was criticized for two main reasons. First, the 


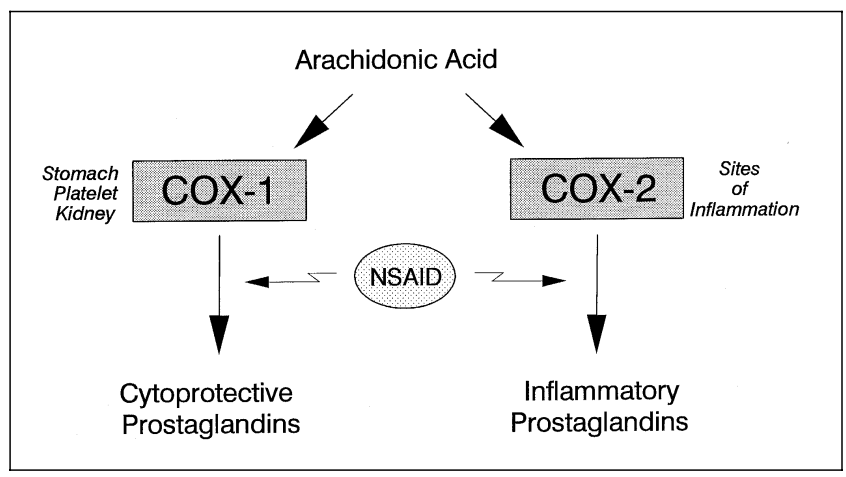

Figure 3) The central principle underlying the strategy of developing a selective, inducible form of cyclo-oxygenase isoform (COX-2) inhibitors. A constitutively expressed form, COX-1, is constitutively expressed in many tissues, including the gastrointestinal tract. This form of COX produces prostaglandins that mediate mucosal defence, and its inhibition leads to tissue injury. COX-2 is induced at sites of inflammation and produces prostaglandins that mediate edema formation and pain. Selective suppression of COX-2 should result in reduced inflammation and pain without causing gastrointestinal injury. NSAID Nonsteroidal antiinflammatory drug

definition of 'ulcer' used (a break in the mucosa of more than $3 \mathrm{~mm}$ in diameter) is questionable because this definition does not clearly distinguish true ulcers from erosions. Second, many patients at greatest risk of NSAID-induced ulcer or gastric bleeding were excluded from the study. A large study was undertaken, partly to address these two criticisms, to determine whether misoprostol can reduce the incidence of serious adverse reactions to NSAIDs, namely upper gastrointestinal bleeding, perforation and gastric outlet obstruction (8). Almost 9000 patients were enrolled in this randomized, double-blind, controlled study. Patients ingested NSAIDs and misoprostol, or NSAIDs and placebo over six months. The incidence of serious adverse effects in the placebo group was $0.947 \%$ (42 of 4433 patients). Misoprostol treatment significantly reduced the incidence of serious adverse effects to $0.567 \%$ ( 25 of 4406 ). Thus, one interpretation of these data is that prophylactic treatment with misoprostol significantly reduces the incidence of serious adverse gastrointestinal events in NSAID users. Another interpretation is that misoprostol failed in $60 \%$ of the patients taking this medication. Because of these results and the cost and the relatively high incidence of adverse effects (incidence of diarrhea is approximately $11 \%$ ) associated with misoprostol, its widespread use for prophylaxis of NSAID gastropathy is of questionable value.

\section{INDUCIBLE PROSTAGLANDIN SYNTHASE:} THE LIGHT AT THE END OF THE TUNNEL?

The existence of multiple forms of the enzyme primarily responsible for prostaglandin synthesis was suggested as far back as 1972. Flower and Vane (44) noted that standard NSAIDs inhibited prostaglandin synthesis in the brain and peripheral tissues. In contrast, acetaminophen only exerted inhibitory activity on prostaglandin synthesis in the brain, suggesting that the enzyme in the brain is different from that in the periphery. In the past few years, distinct forms of prostaglandin synthase have been proven using molecular techniques. It is now clear that there are at least two isoforms of cyclo-oxygenase: a constitutively expressed form referred to as 'COX-1' and an inducible form referred to as 'COX-2'. The latter enzyme has been identified in numerous cells and tissues, including mitogen-treated chicken embryo fibroblasts, endothelial cells, macrophages, chondrocytes, fibroblasts and mesangial cells (45-50). This enzyme can be induced by exposure to various cytokines, mitogens and endotoxin (48-50), and its expression is up-regulated at sites of inflammation (51). Prostaglandins produced in the gastrointestinal tract that play a vital role in maintaining mucosal integrity appear to be derived from COX-1; therefore, suppression of COX-1 activity by NSAIDs is believed to be a crucial factor in the pathogenesis of NSAID gastropathy (Figure 3). It has been suggested that a selective inhibitor of COX-2 would suppress prostaglandin synthesis at sites of inflammation and in response to endotoxin or interleukin-1 (eg, in fever), but would spare constitutive prostaglandin synthesis in the gastrointestinal tract and therefore not be ulcerogenic (52-54). This is discussed in more detail below.

\section{GASTROINTESTINAL-SAFE NSAIDs: THE PAST}

Over the past 30 years a number of strategies have been taken to reduce the gastrointestinal injury caused by NSAIDs. These include coating the NSAID to prevent $a b$ sorption in the stomach, parenteral administration and formulation of pro-drugs that require hepatic metabolism for the cyclo-oxygenase activity to be unmasked. While in each case claims have been made of reduced gastrointestinal irritancy, these modifications have had little impact on the incidence of severe adverse reactions. For example, sulindac is an NSAID that must undergo hepatic metabolism before becoming active and therefore is expected to have reduced topical irritant properties. However, little protective advantage over other NSAIDs is conferred by this formulation $(55,56)$. Enteric-coated ASA may cause less acute, superficial injury to the mucosa (57) but still causes significant ulceration and bleeding (58). Gastric ulcers are also observed when NSAIDs are administered parenterally or intrarectally $(18,19)$. Indeed, there is evidence that with intrarectal administration of NSAIDs, the risk of a significant adverse reaction is increased over that observed with oral administration (19).

While many NSAIDs have been introduced over the past 15 years that have been claimed to have reduced ulcerogenic potential, the long term clinical experience with these compounds has been disappointing. In part this was due to the widespread use of human volunteer studies to substantiate safety. Use of healthy human volunteers doesn't always predict what happens in patients. For example, doses of drugs shown not to cause damage in healthy volunteers are not necessarily innocuous in patients $(56,59)$. Problems also arise when the doses of NSAIDs tested in such studies are lower than that found to be effective for relieving pain and inflammation in the arthritic patient. 


\section{GASTROINTESTINAL-SPARING NSAIDs: THE PRESENT}

There is a growing body of evidence supportive of the claims that two relatively new NSAIDs - etodolac and nabumetone - have markedly reduced capacities for causing gastric ulceration and bleeding compared with previous NSAIDs. Both nabumetone and etodolac have been reported to exert anti-inflammatory and analgesic properties comparable with the most widely prescribed NSAIDs (eg, naproxen, diclofenac). When tested in patients with rheumatoid arthritis or osteoarthritis, however, both compounds produce significantly less severe gastrointestinal complications, results that have been demonstrated in both endoscopic clinical trials and postmarketing surveillance studies. The latter, by virtue of the much larger sample size and typically longer period of drug ingestion, tends to provide more convincing results. For example, in a study in the United Kingdom, almost 11,000 patients taking nabumetone for up to one year for rheumatoid arthritis or osteoarthritis were studied (60). Only 11 serious events were reported during that period $(0.1 \%)$, of which seven were gastrointestinal bleeding. In a German study, only two patients of 8865 treated with nabumetone for arthritis developed gastrointestinal bleeding $(0.02 \%)(61)$, while in a study in the United States, ulcers were reported in only 13 of 1912 patients $(0.7 \%)$ treated with nabumetone (62). In all these postmarketing surveillance studies, therefore, the incidence of serious gastrointestinal complications was well below the $2 \%$ to $4 \%$ range that has been documented for standard NSAIDs (6).

Similar studies with convincing results have been reported for etodolac. Many endoscopic studies have demonstrated reduced gastrointestinal damage compared with that seen with standard NSAIDs. Again, larger clinical trials and postmarketing surveillance studies provide more useful information because they tend to focus on serious adverse effects. In each of three postmarketing surveillance studies very low incidences of serious adverse effects were reported: six of 4947 patients $(0.12 \%)$ treated with etodolac, of which three had ulcers (63); 11 of 3302 etodolac-treated patients (0.3\%) (64); and fewer than $0.1 \%$ of patients receiving etodolac $(63,64)$. Etodolac was also found to have other favourable properties compared with other NSAIDs, including the lack of interaction with plasma clearance of warfarin (65).

Why do etodolac and nabumetone produce less gastrointestinal injury while still being potent anti-inflammatory and analgesic agents? There are several possible answers. Because nabumetone is nonacidic it is expected to have reduced topical irritant properties. Nabumetone is also formulated as a pro-drug; the compound has very weak inhibitory activity on cyclo-oxygenase isoforms (COX), but is metabolized by the liver to 6-methoxy-2-naphthylacetic acid, which is a much more potent COX inhibitor. Unlike nabumetone, etodolac is an acidic compound and is not formulated as a pro-drug. As outlined above, enterohepatic recirculation of NSAIDs may be a key factor in the pathogenesis of NSAID enteropathy. Nabumetone and etodolac do not undergo en- terohepatic recirculation. Another common feature of these two drugs that likely contributes to their good gastrointestinal tolerance is their weak inhibitory activity on gastrointestinal prostaglandin synthesis, despite being able to suppress prostaglandin synthesis potently at sites of inflammation (66-68). The reason for this discrepancy in effects on prostaglandin synthesis in different tissues is most likely related to differential potencies on the two known forms of COX. These drugs can be described as being 'COX-2 selective', although they do not exhibit the high degree of selectivity for this enzyme as shown with a number of recently developed compounds (outlined in more detail below). Etodolac is approximately 10 times more potent as an inhibitor of COX-2 than of COX-1 (69). For the active metabolite of nabumetone, the ratio is approximately 7:1 (70). It should be noted that these drugs were not specifically designed to be COX-2 selective inhibitors. Indeed, both compounds were developed before the existence of COX-2 was proven. However, it is possible that the marginal selectivity for COX-2 seen with these compounds may yield certain benefits over newer compounds that are more than 100 -fold more selective for COX-2 than for COX-1.

\section{GASTROINTESTINAL-SPARING NSAIDs: THE FUTURE}

Highly selective COX-2 inhibitors: Considerable effort on the part of numerous pharmaceutical companies is being directed towards the development of highly selective inhibitors of COX-2. NSAIDs currently on the market show considerable variability in their potency as inhibitors of COX-2, but virtually all are far more potent inhibitors of COX-1 $(53,54)$. As outlined above, the exceptions, nabumetone and etodolac, are somewhat more potent inhibitors of COX-2 and appear to have reduced gastrointestinal toxicity. However, it is possible that the retained ability of these drugs to suppress COX-1 contributes to some of their anti-inflammatory and analgesic effects. Some highly selective COX-2 inhibitors have been described, including L745,337 (70) and SC 58125 (71). In studies involving acute administration, these compounds did not cause as much damage as standard NSAIDs in the stomach of experimental animals $(70,71)$. As discussed in more detail below, studies involving chronic administration of highly selective COX-2 inhibitors or, with the exception of a single study (72), involving administration to animals with pre-existing gut inflammation, have not been reported. Also, it is unclear whether these compounds will exhibit the same effectiveness in reducing pain and inflammation as existing NSAIDs. Appropriate clinical evaluation of highly selective COX-2 inhibitors is eagerly awaited.

The pursuit of a highly selective COX-2 inhibitor appears to be a sound approach to developing gastrointestinal-sparing anti-inflammatory drugs. Recently, numerous claims of new NSAIDs that spare the gastrointestinal tract have been made; because, for the most part, these drugs have not lived up to their advanced billing, a certain degree of scepticism is probably prudent until convincing clinical data are available. There are significant questions regarding the hypothesis that 


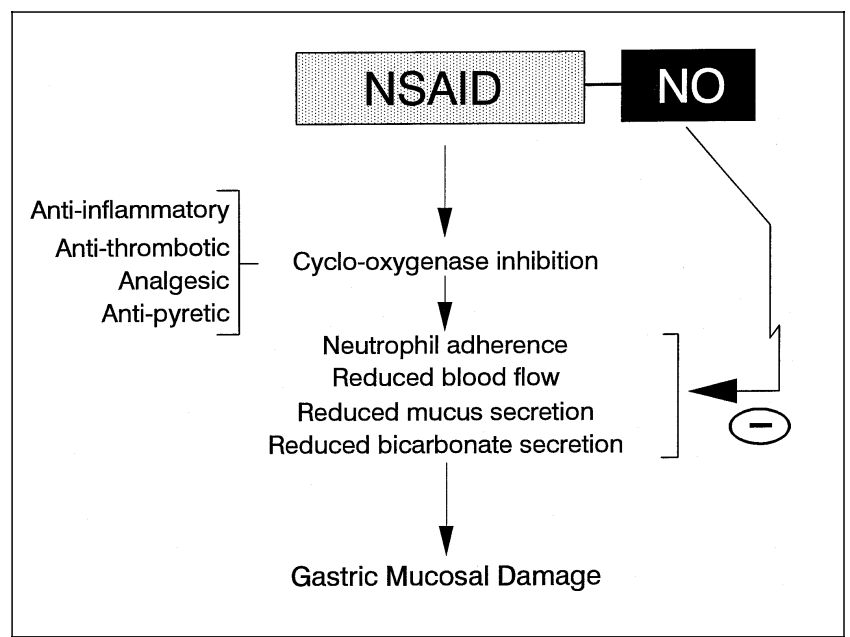

Figure 4) The principle underlying the development of nitric oxidereleasing nonsteroidal anti-inflammatory drug (NSAID) derivatives (NO-NSAIDs). By suppressing prostaglandin synthesis (cyclo-oxygenase activity), NSAIDs stimulate neutrophil adherence to the vascular endothelium, reduce mucosal bloodflow, and inhibit mucus and bicarbonate secretion, all of which contribute to ulcer development. Nitric oxide released from the NO-NSAID can counteract each of these effects of the NSAID moiety, thereby preventing mucosal injury. However, the nitric oxide moiety does not interfere with cyclo-oxygenase suppression, and therefore does not affect the ability of the compound to reduce inflammation, fever or pain, or to inhibit platelet aggregation

highly selective COX-2 inhibitors will be effective analgesic and anti-inflammatory drugs but will spare the gastrointestinal tract of injury. These include the following.

- If COX-2 is primarily responsible for the production of prostanoids that mediate inflammation, pain and fever, it is unlikely that highly selective inhibitors of COX-2 will be more therapeutically effective than existing NSAIDs, since many of the existing NSAIDs are very effective inhibitors of COX-2 $(53,54)$.

- It is possible that prostanoids produced via COX-1 contribute to inflammation, pain and fever. If this proves to be true, highly selective COX-2 inhibitors will be less effective anti-inflammatory, analgesic and antipyretic agents than existing NSAIDs, which block both forms of COX (eg, etodolac, nabumetone, diclofenac).

- COX-2 may produce prostaglandins that carry out important physiological functions; therefore, highly selective COX-2 inhibitors may produce adverse reactions not seen with standard NSAIDs. For example, COX-2 has been shown to be expressed in human fetal membranes at term, and it has been suggested that it is the prostaglandins produced by this form of COX that are responsible for the initiation and maintenance of labour (73).

- Most gastrointestinal ulceration is associated with significant mucosal inflammation. In these circumstances it is likely that COX-2 is expressed.
Moreover, it is possible that the prostaglandins derived from COX-2 in these circumstances are responsible for maintaining mucosal integrity and promoting healing. It is well known that NSAIDs retard the healing of ulcers (74). Matsuda and colleagues (75) recently reported that, in a mouse model of gastric ulcer, there was a profound increase in expression of mRNA for COX-2 during development of the ulcers, with a parallel rise in prostaglandin synthesis, but no changes in mRNA for COX-1 were detected. These observations suggest that COX-2 is an important source of prostaglandins when an ulcer is present. Similar results have been reported for human gastric tissue. COX-1 and COX-2 protein and mRNA were observed in both normal and ulcerated tissue, with COX-2 being more prominent than COX-1 in the mucosa of gastric ulcer patients (76).

- As outlined above, the damage produced by NSAIDs in the small intestine may occur through a mechanism different from that in the stomach; specifically, NSAID-induced enteropathy may not be related to suppression of prostaglandin synthesis. If this is the case, there is no reason to believe that a new NSAID that spares gastrointestinal prostaglandin synthesis will spare the small intestine of injury. The relatively selective COX-2 inhibitors currently on the market (etodolac, nabumetone) appear to spare the small intestine. However, this feature can be explained by other properties of these drugs, most notably that they do not undergo enterohepatic recirculation.

- Because platelets contain only COX-1, and it is this enzyme that is responsible for production of the pro-thrombotic substance thromboxane, a selective COX-2 inhibitor would not exert any antithrombotic activity. Thus, highly selective COX-2 inhibitors would not have the same use as ASA in the prophylaxis of stroke and myocardial infarction (77).

Nitric oxide-releasing NSAID derivatives: Nitric oxide is increasingly being recognized as a critical mediator of gastrointestinal mucosal defence. Interestingly, there is considerable overlap between the functions performed by prostaglandins and those performed by nitric oxide. For example, both modulate mucosal bloodflow, stimulate mucus release, facilitate repair of injury and inhibit activation of leukocytes. Like prostaglandins, nitric oxide or a nitric oxide donor can reduce the severity of experimental gastric damage (78). Based on evidence suggesting that reduced gastrointestinal bloodflow and activation of neutrophils play critical roles in the pathogenesis of NSAID-induced gastric injury, the present author proposed that the linking of a nitric oxide-releasing moiety to an NSAID may reduce its toxicity (Figure 4). If this derivation did not interfere with the ability of the NSAID to suppress cyclo-oxygenase activity, all the beneficial effects of the NSAID should ideally be retained. This hypothesis has now been proven in experimental models of 
NSAID-induced gastroenteropathy. Nitric oxide-releasing derivatives of flurbiprofen, ketoprofen and diclofenac (collectively referred to as 'NO-NSAIDs') have been shown to spare the gastrointestinal tract, even when given repeatedly over several weeks (79-81). Each of these compounds has anti-inflammatory activity comparable with that of the parent NSAID, and can suppress gastric prostaglandin synthesis as effectively. NO-NSAIDs also exhibit antipyretic activity comparable with that of their parent compounds (82). These derivatives inhibit both COX-1 and COX-2, with similar selectivity as the parent NSAIDs, without being metabolized, indicating that these derivatives are not pro-drugs (83). Despite evidence that these agents generated nitric oxide in the rat in vivo, these compounds did not significantly affect systemic arterial blood pressure $(79,80)$.

Concerns were noted above regarding the potential detrimental effects of selective COX-2 inhibitors in situations where the gastrointestinal mucosa is inflamed; there is the possibility that inhibition of COX-2 expression would lead to inhibition of the prostaglandins (which may perform important physiological functions) produced via this enzyme. Because NO-NSAIDs block COX-1 and COX-2 as effectively as the parent NSAIDs (83), the same concerns can be raised about this class of compounds. However, studies in animal models of chronic colitis (81) and gastric ulcer (72) have been performed in which NO-NSAIDs were administered daily for one week. In the case of colitis, the NONSAID did not cause an exacerbation of mucosal injury and inflammation, whereas standard NSAIDs did (81). In the case of gastric ulcer, daily treatment with an NO-NSAID accelerated healing in this rat model (72).

Unlike selective inhibitors of COX-2, NO-NSAIDs are capable of inhibiting platelet thromboxane synthesis and therefore platelet aggregation. The antithrombotic effects of a nitric oxide-releasing derivative of ASA were recently evaluated in the rat. This compound was found to have markedly enhanced antithrombotic effects without causing significant gastric damage or affecting systemic blood pressure (84). Thus, a nitric oxide-releasing ASA derivative may be suitable for long term prevention of myocardial infarction and stroke. ASA is increasingly used for these indications $(77,85,86)$, but even with the low doses that are commonly employed there is a significant increase in the incidence of

\section{REFERENCES}

1. Vane JR. Inhibition of prostaglandin synthesis as a mechanism of action for aspirin-like drugs. Nature 1971;231:232-5.

2. Picot D, Loll PJ, Garavito RM. The $x$-ray crystal structure of the membrane protein prostaglandin $\mathrm{H}_{2}$ synthase-1. Nature 1994;367:243-9.

3. Cronstein BN, Weissmann G. Targets for antiinflammatory drugs. Annu Rev Pharmacol Toxicol 1995;35:449-62.

4. Wu KK, Sanduja R, Tsai A, Ferhanoglu B, Loose-Mitchell DS. Aspirin inhibits interleukin 1 -induced prostaglandin $\mathrm{H}$ synthase expression in cultured endothelial cells. Proc Natl Acad Sci USA 1991;88:2384-7.

5. Lanza FL. Gastrointestinal toxicity of newer NSAIDs. Am J Gastroenterol 1993;88:1318-23.

6. Paulus HE. FDA arthritis advisory committee meeting: serious gastrointestinal toxicity of nonsteroidal antiinflammatory drugs, etc. Arthritis Rheum 1988;31:1450-1. gastrointestinal bleeding and other hemostatic complications (85-87). For example, in a recent preliminary report, $10 \mathrm{mg} /$ day ASA was found to increase endoscopic scores significantly for gastric damage (87).

Unfortunately, clinical data on NO-NSAIDs are not available. Whether the promising results obtained in animal studies are predictive of what will happen in a clinical setting remains to be seen. To quote a recent editorial comment by Hawkey (88), the exciting experimental work on NO-NSAIDs "if translated into human terms, would suggest that NO-NSAIDs could well have advantages over both new NSAIDs and no NSAIDs".

\section{SUMMARY}

While it has seemed unlikely that the ulcerogenic properties of NSAIDs could be separated from their beneficial effects because both are inextricably linked to suppression of prostaglandin synthesis, there are encouraging developments suggesting that gastrointestinal-sparing NSAIDs are attainable. Newly developed NSAIDs that show some selectivity for the inducible form of prostaglandin synthase (COX-2), such as etodolac and nabumetone, have greatly reduced gastrointestinal toxicity in treating rheumatoid and osteoarthritis. Development of highly selective COX-2 inhibitors may be a rational approach to developing potent anti-inflammatory agents that spare the gastrointestinal tract, although a number of concerns about this strategy still need to be addressed. An alternative approach, which involves the linking of a nitric oxide-releasing moiety to standard NSAIDs, has shown great promise in experimental models, but has not cleared the hurdle of demonstrated efficacy without toxicity in a clinical setting. When one considers the developments that have been made in the very recent past, and the promising developments being made at present, it is entirely possible that in the not-too-distant future, NSAID-induced gastroenteropathy will soon be a thing of the past.

ACKNOWLEDGEMENTS: Dr Wallace is a Medical Research Council of Canada (MRC) Senior Scientist and an Alberta Heritage Foundation for Medical Research Scientist, and is supported by research funding from the MRC and the Crohn's and Colitis Foundation of Canada.

7. Graham DY, Agrawal NM, Roth SH. Prevention of NSAID-induced gastric ulcer with misoprostol: multicentre, double-blind, placebo-controlled trial. Lancet 1988;ii:1277-80.

8. Silverstein FE, Graham DY, Senior RJ, et al. Misoprostol reduces serious gastrointestinal compliations in patients with rheumatoid arthritis receiving nonsteroidal anti-inflammatory drugs. Ann Intern Med 1995;123:241-9.

9. Bjarnason I, Hayllar J, MacPherson AJ, Russell AS. Side effects of nonsteroidal anti-inflammatory drugs on the small and large intestine in humans. Gastroenterology 1993;104:1832-47.

10. Bjarnason I, Zanelli G, Smith PP, et al. Nonsteroidal antiinflammatory drug-induced intestinal inflammation in humans. Gastroenterology 1987;93:480-9.

11. Lang J, Price AB, Levi AJ, Burke M, Gumpel JM, Bjarnason I. Diaphragm disease: Pathology of disease of the small intestine induced by non-steroidal anti-inflammatory drugs. J Clin Pathol 1988;41:516-26 
12. Kaufmann HJ, Taubin HL. Nonsteroidal anti-inflammatory drugs activate quiescent inflammatory bowel disease. Ann Intern Med 1987;107:513-6.

13. Bloom BS. Direct medical costs of disease and gastrointestinal side effects during treatment of arthritis. Am J Med 1988;83(Suppl 2A):20-4.

14. Wallace JL, Tigley AW. New insights into prostaglandins and mucosal defence. Aliment Pharmacol Ther 1995;9:227-35.

15. Lanza FL. A review of gastric ulcer and gastroduodenal injury in normal volunteers receiving aspirin and other nonsteroidal anti-inflammatory drugs. Scand J Gastroenterol 1989;24(Suppl 163):24-31.

16. Fromm D. How do non-steroidal anti-inflammatory drugs affect gastric mucosal defenses? Clin Invest Med 1987;10:251-8.

17. Somasundaram S, Hayllar H, Rafi S, Wrigglesworth JM, Macpherson AJS, Bjarnason I. The biochemical basis of non-steroidal anti-inflammatory drug-induced damage to the gastrointestinal tract: a review and a hypothesis. Scand J Gastroenterol 1995;30:289-99.

18. Estes LL, Fuhs DW, Heaton AH, Butwinick CS. Gastric ulcer perforation, associated with the use of injectable ketorolac. Ann Pharmacother 1993;27:42-3.

19. Henry D, Dobson A, Turner C. Variability in the risk of major gastrointestinal complications from nonaspirin nonsteroidal anti-inflammatory drugs. Gastroenterology 1993;10:1078-88,

20. Prichard PJ, Kitchingman GK, Walt RP, Daneshmend TK, Hawkey CJ. Human gastric mucosal bleeding induced by low dose aspirin, but not warfarin. BMJ 1989;298:493-6.

21. Hawkey CJ, Hawthorne AB, Hudson N, Cole AT, Mahida YR, Daneschmend TK. Separation of the impairment of haemostasis by aspirin from mucosal injury in the human stomach. Clin Sci 1991;81:565-73.

22. Wallace JL, McKnight W, Miyasaka M, et al. Role of endothelial adhesion molecules in NSAID-induced gastric mucosal injury. Am J Physiol 1993;265:G993-8.

23. Kitahora T, Guth PH. Effect of aspirin plus hydrochloric acid on the gastric mucosal microcirculation. Gastroenterology 1987;93:810-7.

24. Asako H, Kubes P, Wallace JL, Gaginella T, Wolf RE, Granger DN Indomethacin-induced leukocyte adhesion in mesenteric venules: role of lipoxygenase products. Am J Physiol 1992;262:G903-8.

25. Asako H, Kubes P, Wallace JL, Wolf RE, Granger DN. Modulation of leukocyte adhesion to rat mesenteric venules by aspirin and salicylate. Gastroenterology 1992;103:146-52.

26. Wallace JL, McCafferty D-M, Carter L, McKnight W, Argentieri D. Tissue-selective inhibition of prostaglandin synthesis in rat by tepoxalin: anti-inflammatory without gastropathy. Gastroenterology 1993;105:1630-6.

27. Wallace JL, Keenan CM, Granger DN. Gastric ulceration induced by nonsteroidal anti-inflammatory drugs is a neutrophil-dependent process. Am J Physiol 1990;259:G462-7.

28. Lee M, Lee AK, Feldman M. Aspirin-induced acute gastric mucosal injury is a neutrophil-dependent process in rats. Am J Physiol 1992;263:G920-6.

29. Wallace JL, Arfors K-E, McKnight GW. A monoclonal antibody against the CD18 leukocyte adhesion molecule prevents indomethacin-induced gastric damage in the rabbit. Gastroenterology 1991;100:878-83.

30. Wallace JL, Granger DN. The pathogenesis of NSAID-gastropathy are neutrophils the culprits? Trends Pharmacol Sci 1992;13:129-31.

31. Kitahora T, Guth PH. Effect of aspirin plus hydrochloric acid on the gastric mucosal microcirculation. Gastroenterology 1987;93:810-7.

32. Ashley SW, Sonnenschein LA, Cheung LY. Focal gastric mucosal blood flow at the site of aspirin-induced ulceration. Am J Surg 1985;149:53-9.

33. Gana TJ, Huhlewych R, Koo J. Focal gastric mucosal blood flow in aspirin-induced ulceration. Ann Surg 1987;205:399-403.

34. Whittle BJR. Temporal relationship between cyclooxygenase inhibition, as measured by prostacyclin biosynthesis, and the gastrointestinal damage induced by indomethacin in the rat. Gastroenterology 1981;80:94-8.

35. Yamada T, Deitch E, Specian RD, Perry MA, Sartor RB, Grisham MB. Mechanisms of acute and chronic intestinal inflammation induced by indomethacin. Inflammation 1993;17:641-62.

36. Kent TH, Cardelli RM, Stemler FW. Small intestinal ulcers and intestinal flora in rats given indomethacin. Am J Pathol 1969:54:237-45.

37. Bjarnason I, Hayllar J, Smethurst P, Price A, Gumpel MJ.
Metronidazole reduces intestinal inflammation and blood loss in non-steroidal anti-inflammatory drug induced enteropathy. Gut 1992;33:1204-8

38. Robert A. Resistance of germfree rats to indomethacin-induced intestinal lesions. Prostaglandins 1977;14:333-41.

39. Yesair DW, Callahan M, Remington L, Kensler CJ. Role of the entero-hepatic cycle of indomethacin on its metabolism, distribution in tissues and its excretion by rats, dogs and monkeys. Biochem Pharmacol 1970;19:1579-90.

40. Robinson MG, Griffin JW, Bowers J, et al. Effect of ranitidine on gastroduodenal damage induced by nonsteroidal anti-inflammatory drugs. Dig Dis Sci 1989;34:424-8.

41. Ehsanullah RSB, Page MC, Tildesly G, Wood JR. Prevention of gastroduodenal damage induced by non-steroidal anti-inflammatory drugs: controlled trial of ranitidine. BMJ 1988;297:1017-21.

42. Daneshmend TK, Stein AG, Bhaskar NK, Hawkey CJ. Abolition by omeprazole of aspirin induced gastric mucosal injury in man. Gut 1990;31:514-7.

43. Graham DY, White RH, Moreland JW, et al. Duodenal and gastric ulcer prevention with misoprostol in arthritis patients taking NSAIDs. Ann Intern Med 1993;119:257-62.

44. Flower RJ, Vane JR. Inhibition of prostaglandin synthetase in brain explains the anti-pyretic activity of paracetamol (4-acetamide-phenol). Nature 1972;120:412-1.

45. Xie W, Chipman JG, Robertson DL, Erikson RL, Simmons DL. Expression of a mitogen-responsive gene encoding prostaglandin synthase is regulated by mRNA splicing. Proc Natl Acad Sci USA 1991;88:2692-6.

46. Jackson BA, Goldstein RH, Roy R, Cozzani M, Taylor L, Polgar P. Effects of transforming growth factor $\beta$ and interleukin- $1 \beta$ on expression of cyclooxygenase 1 and 2 and phospholipase $A_{2}$ mRNA in lung fibroblasts and endothelial cells in culture. Biochem Biophys Res Commun 1993;197:1465-74.

47. Hempel SL, Monick MM, Hunninghake GW. Lipopolysaccharide induces prostaglandin $\mathrm{H}$ synthase-2 protein and mRNA in human alveolar macrophages and blood monocytes. J Clin Invest 1994;93:391-6.

48. Martin M, Neumann D, Hoff T, Resch K, DeWitt DL, Goppelt-Struebe M. Interleukin-1-induced cyclooxygenase 2 expression is suppressed by cyclosporin A in rat mesangial cells. Kidney Int 1994:45:150-8.

49. Lyons-Giordano B, Pratta MA, Galbraith W, Davis GL, Arner EC. Interleukin-1 differentially modulates chondrocyte expression of cyclooxygenase-2 and phospholipase $\mathrm{A}_{2}$. Exp Cell Res 1993;206:58-62.

50. Habib A, Créminon C, Frobert Y, Grassi J, Pradelles P, Maclouf J. Demonstration of an inducible cyclooxygenase in human endothelial cells using antibodies raised against the carboxyl-terminal region of the cyclooxygenase-2. J Biol Chem 1993;268:23448-54.

51. Vane JR, Mitchell JA, Appleton I, et al. Inducible isoforms of cyclooxygenase and nitric oxide synthase in inflammation. Proc Natl Acad Sci USA 1994;91:2046-50.

52. Xie W, Robertson DL, Simmons DL. Mitogen-inducible prostaglandin $\mathrm{G} / \mathrm{H}$ synthase: A new target for nonsteroidal antiinflammatory drugs. Drug Dev Res 1992;25:249-65.

53. Mitchell JA, Akarasereenont P, Thiemermann C, Flower RJ, Vane JR. Selectivity of nonsteroidal antiinflammatory drugs as inhibitors of constitutive and inducible cyclooxygenase. Proc Natl Acad Sci USA 1993;90:11693-7.

54. Meade EA, Smith WL, DeWitt DL. Differential inhibition of prostaglandin endoperoxide synthase (cyclooxygenase) isozymes by aspirin and other non-steroidal anti-inflammatory drugs. J Biol Chem 1993;268:6610-4.

55. Graham DY, Smith JL, Holmes GI, Davies RO. Nonsteroidal anti-inflammatory effect of sulindac sulfoxide and sulfide on gastric mucosa. Clin Pharmacol Ther 1985;38:65-70.

56. Carson JL, Strom BL, Morse L, et al. The relative gastrointestinal toxicity of the nonsteroidal anti-inflammatory drugs. Arch Intern Med 1987;147:1054-9.

57. Hawthorne AB, Mahida YR, Cole AT, Hawkey CJ. Aspirin-induced gastric mucosal damage: prevention by enteric-coating and relation to prostaglandin synthesis. Br J Clin Pharmacol 1991;32:7-83.

58. Hoftiezer JW, Silvoso GR, Burks M, Ivey KJ. Comparison of the effects of regular and enteric-coated aspirin on gastroduodenal mucosa of man. Lancet 1980;ii:609-12.

59. Lanza FL, Nelson RS, Rack MF. A controlled endoscopic study 
comparing the toxic effects of sulindac, naproxen, aspirin and placebo on the gastric mucosal of healthy volunteers. J Clin Pharmacol 1984:24:89-95.

60. Jenner PN. A 12-month postmarketing surveillance study of nabumetone. A preliminary report. Drugs 1990;40(Suppl 5):80-6

61. Stroehmann I, Fedder M, Zeidler H. German drug monitoring studies with nabumetone. Drugs 1990;40(Suppl 5):38-42.

62. Willkens RF. An overview of the long-term safety experience of nabumetone. Drugs 1990;40(Suppl 5):34-7.

63. Benhamou CL. Large-scale open trials with etodolac $\left(\right.$ Lodine $^{\circledR}$ ) in France: an assessment of safety. Rheumatol Int 1990;10(Suppl):29-34.

64. Schattenkirchner M. An updated safety profile of etodolac in several thousand patients. Eur J Rheumatol Inflamm 1990;10:56-65.

65. Zvaifler N. A review of the antiarthritic efficacy and safety of etodolac. Clin Rheumatol 1989;8:43-53.

66. Jeremy JY, Mikhailidis DP, Barradas MA, et al. The effect of nabumetone and its principal active metabolite on in vitro human gastric mucosal prostanoid synthesis and platelet function. $\mathrm{Br} \mathrm{J}$ Rheumatol 1990;29:116-9.

67. Melarange R, Gentry C, Durie M, O'Connell C, Blower PR. Gastrointestinal irritancy, antiinflammatory activity, and prostanoid inhibition in the rat: differentiation of effects between nabumetone and etodolac. Dig Dis Sci 1994:39:601-8.

68. Russell RI. Endoscopic evaluation of etodolac and naprosen and their relative effects on gastric and duodenal prostaglandins. Rheumatol Int 1990;19(Suppl):17-21

69. Glaser K, Sung M-L, O’Neill K, et al. Etodolac selectively inhibits human prostaglandin $\mathrm{G} / \mathrm{H}$ synthase 2 (PGHS-2) versus human PGHS-1. Eur J Pharmacol 1995;281:107-11.

70. Chan CC, Gordon R, Brideau C, et al. In vivo pharmacology of L-745,337: A novel non-steroidal antiinflammatory agent (NSAID) with an ulcerogenic sparing effect in rat and monkey stomach. Can J Physiol Pharmacol 1994;72:266.

71. Masferrer JL, Zweifel BS, Manning PT, et al. Selective inhibition of inducible cyclooxygenase 2 in vivo is antiinflammatory and nonulcerogenic. Proc Natl Acad Sci USA 1994;91:3228-32.

72. Elliott SN, McKnight W, Cirino G, Wallace JL. A nitric oxide-releasing NSAID accelerates gastric ulcer healing in rats. Gastroenterology 1995;109:524-30.

73. Slater DM, Berger LC, Newton R, Moore GE, Bennett PR. Expression of cyclooxygenase types 1 and 2 in human fetal membranes at term. Am J Obstet Gynecol 1995;172:77-82.

74. Stadler P, Armstrong D, Margalith D, et al. Diclofenac delays healing of gastroduodenal mucosal lesions. Double-blind, placebo-controlled endoscopic study in healthy volunteers. Dig Dis Sci 1991;36:594-600.

75. Matsuda K, Sakamoto C, Mizuno H, et al. Gene expression of cyclooxygenase and EGF-like growth factors in different stages of the mouse gastric ulcer. Gastroenterology 1994;106:A132.

76. Kawahito Y, Sano H, Mukai S, et al. Detection of cyclooxygenase-1 and -2 proteins and mRNA in gastric ulcer. Pathophysiology 1994;1:288.

77. Patrono C. Aspirin as an antiplatelet drug. N Engl J Med 1994;330:1287-94.

78. MacNaughton WK, Cirino G, Wallace JL. Endothelium-derived relaxing factor (nitric oxide) has protective actions in the stomach. Life Sci 1989;45:1869-76.

79. Wallace JL, Reuter B, Cicala C, McKnight W, Grisham MB, Cirino G. Novel nonsterodial anti-inflammatory drug derivatives with markedly reduced ulcerogenic properties in the rat. Gastroenterology 1994;107:173-9.

80. Wallace JL, Reuter B, Cicala C, McKnight W, Grisham MB, Cirino G. A diclofenac derivative without ulcerogenic properties. Eur J Pharmacol 1994;257:249-55.

81. Reuter BK, Cirino G, Wallace JL. Markedly reduced intestinal toxicity of a diclofenac derivative. Life Sci 1994;55:PL1-8.

82. Wallace JL, Pittman QJ, Cirino G. Nitric oxide releasing NSAIDs: a novel class of GI-sparing anti-inflammatory drugs. In: Proznansky W, ed. New Molecular Approaches to Anti-Inflammatory Therapy. Basel: Birkhäuser Verlag, 1995:121-9.

83. Mitchell JA, Cirino G, Akarasereenont P, Wallace JL, Flower RJ, Vane JR. Flurbinitroxybutylester: a novel anti-inflammatory drug devoid of ulcerogenic activity, inhibits cyclo-oxygenase- 1 and cyclo-oxgenase-2. Can J Physiol Pharmacol 1994;72:270.

84. Wallace JL, McKnight W, Del Soldato P, Baydoun AR, Cirino G. Anti-thrombotic effects of a nitric oxide-generating, gastric-sparing aspirin derivative. J Clin Invest 1995;96:2711-8.

85. The SALT Collaborative Group. Swedish Aspirin Low-Dose Trial (SALT) of $75 \mathrm{mg}$ aspirin as secondary prophylaxis after cerebrovascular ischaemic events. Lancet 1991;338:1345-9.

86. Meade TW, Roderick PJ, Brennan PJ, Wilkes HC, Kelleher CC. Extracranial bleeding and other symptoms due to low dose aspirin and low intensity oral anticoagulation. Thromb Haemost 1992;68:1-6.

87. Cryer B, Luk G, Feldman M. Effects of very low doses of aspirin (ASA) on gastric, duodenal \& rectal prostaglandins (PGs) \& mucosal injury. Gastroenterology 1995;108:A77.

88. Hawkey CJ. Future treatments for arthritis: new NSAIDs, NO NSAIDs or no NSAIDs? Gastroenterology 1995;109:614-6. 


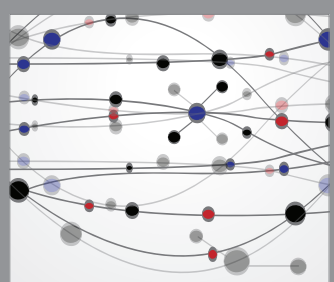

The Scientific World Journal
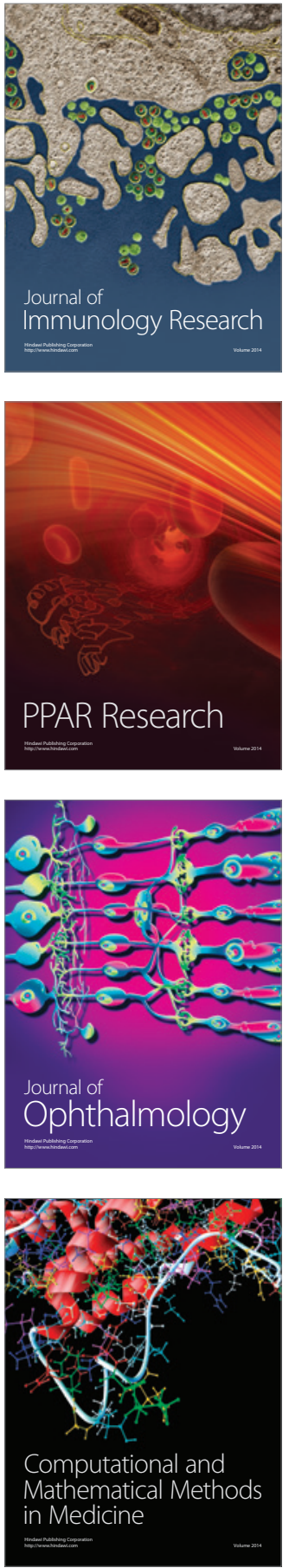

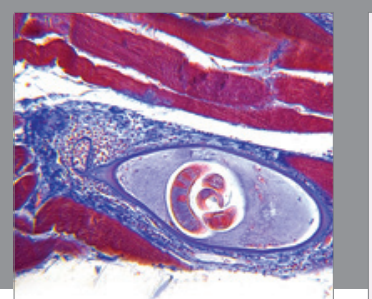

Gastroenterology Research and Practice

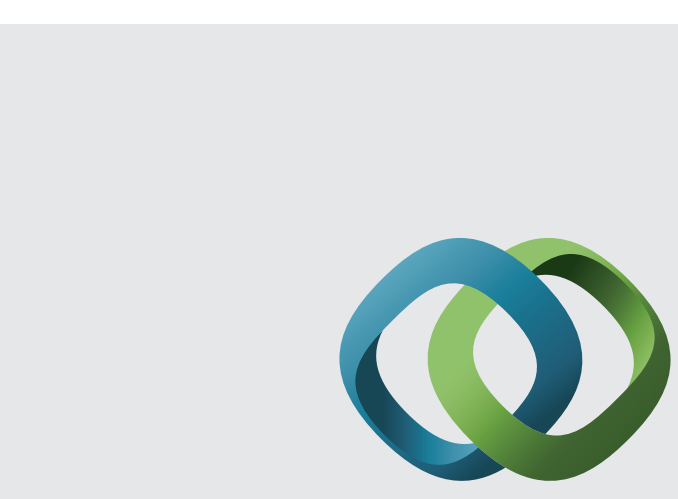

\section{Hindawi}

Submit your manuscripts at

http://www.hindawi.com
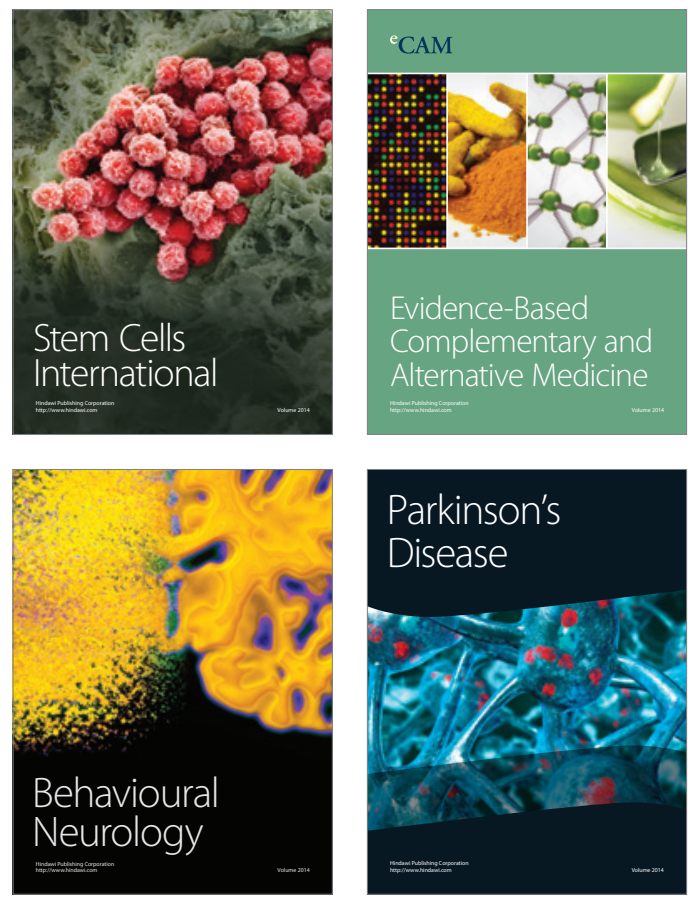
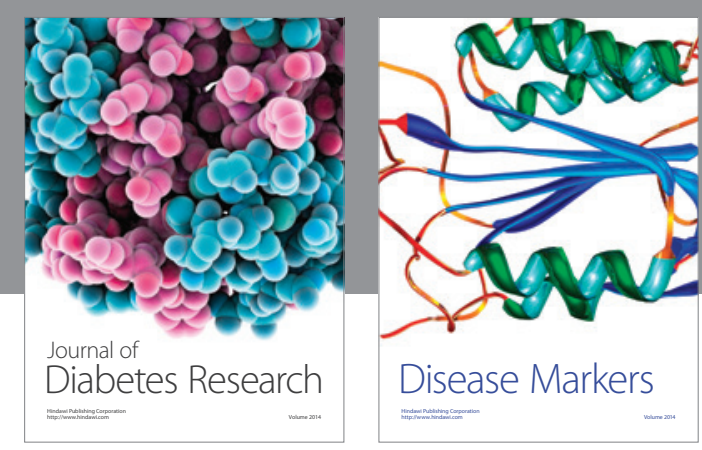

Disease Markers
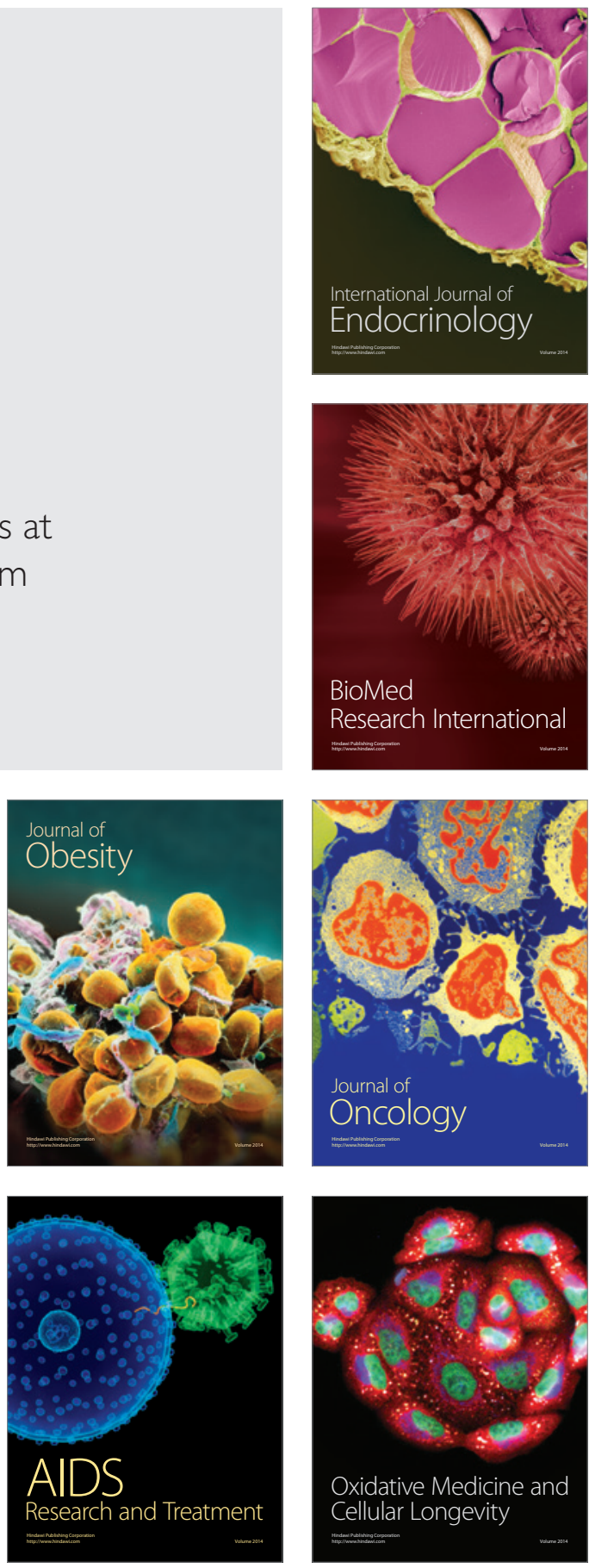